\title{
ETNOMATEMATIKA PADA KEBIASAAN ORANG SUNDA DALAM MENENTUKAN TANGGAL PERNIKAHAN DAN KECOCOKAN PASANGAN PENGANTIN.
}

\author{
Ramli $^{1)}$ \\ ${ }^{1}$ Fakultas Keguruan dan Ilmu Pendidikan, Universitas Muhammadiyah Sukabumi \\ Email: ramlidena93@gmail.com
}

\begin{abstract}
Abstrak.
Artikel ini bertujuan untuk mendalami konsep matematika dalam kebiasaan orang sunda dalam menghitung untuk menentukan tanggal pernikahan dan menentukan kecocokan pasangan pengantin. Jenis metode yang digunakan adalah metode study pustaka yang merupakan telaah dari literatur dari jurnal. Teknik pengumpulan data dengan analisis, menyajikan data dan memberi kesimpulan. Berdasarkan hasil study pustaka ternyata terdapat beberapa unsur matematika di dalam kebiasaan perhitungan orang sunda, yaitu aritmatika modulo dan barisan aritmatika pada aktivitas menentukan tanggal baik untuk menyelenggarakan pernikahan dan menentukan kecocokan pasangan pengantin.
\end{abstract}

Kata kunci: Etnomatematika, aktivitas orang sunda, pernikahan, kecocokan pengantin.

\section{PENDAHULUAN.}

Pendidikan dan budaya merupakan satu kesatuan yang tidak dapat dipisahkan dalam kehidupan kita sehari-hari (Komarudin et al., 2020; Lestari et al., 2020; Wahyuni \& Pertiwi, 2017) karena Pendidikan merupakan kebutuhan mendasar bagi individu dalam masyarakat sedangkan budaya merupakan satu kesatuan yang utuh yang berlaku dalam suatu masyarakat. Budaya merupakan suatu nilai dan ide yang diciptakan oleh sekelompok orang atau masyarakat tertentu da diwariskan dari generasi ke generasi. Koentjaraningrat (1987:9), budaya (kebudayaan) adalah "keseluruhan gagasan dan karya manusia yang harus dibiasakannya dengan belajar beserta keseluruhan dari hasil budi dan karyanya itu". Tujuan dari Pendidikan adalah untuk melestariskan nilai-nilai budaya dari generasi ke generasi.

Seiring perkembangan zaman dan teknologi yang makin berkembang pesat saat ini, budaya lokalpun mendapat tantangan yang cukup berat dimana para pemuda-pemudi sang penerus kurang memperhatikan dan meminati unsur-unsur yang terdapat dalam budaya lokal. Sementara itu pembelajaran tentang budaya atau yang biasa disebut muatan local di daerah tersebut masih berpatokan pada buku tanpa melihat lebih dekat unsur-unsur budaya yang diwariskan pada daerah tersebut.
Salah satu mata pelajaran yang dapat dikaitkan dengan budaya adalah matematika. Masalah-masalah dalam matematika dituntut untuk lebih kontekstual sesuai dengan budaya dan lingkungan sekitar siswa. Pembelajaran matematika berbasis budaya yang biasa disebut etnomatematika (Aini et al., 2018) megacu pada konsep-konsep matematika yang tertanam pada peraktik-peraktik budaya dan mengakui bahwa budaya dan semua orang mengembangkan metode unik memahami dan mengubah realitas komunitas budaya (Orey, 2000). Salah satu praktik budaya yang dapat diamati adalah budaya perhitungan urang sunda. Rumusan masalah dan tujuan yang akan dijawab dalam penelitian ini adalah mengetahui gambaran mengenai budaya perhitunagn urang sunda, pengaruh budaya perhitungan tersebut dalam kehidupan masyarakat setempat, dan unsur-unsur matematika yang terkandung dalam budaya perhitungan urang sunda.

Indonesia merupakan suatu negara dengan jumlah pulau terbanyak di dunia yang di dalamnya terdapat 1331 suku (BPS, 2005:4) yang tentu kaya dengan keanekaragaman budaya yang bisa mendorong untuk memperkaya dan mengembangkan suatu bidang ilmu pengetahuan (Novitasari et al., 2019) serta merupakan potensi yang strategis dijadikan tempat untuk penelitian dalam pengembangan ilmu etnomatematika. Salah satu suku dengan kelompok etnis adat terbesar di Indonesia adalah suku sunda 
yang terletak dibagian barat pulau jawa (Darmayanti, 2013:1). Dalam Bahasa daerahnya, orang sunda juga biasa disebut Urang Sunda. Seseorang bisa dikatakan sebagai urang sunda bilamana orang sunda itu sendiri mempunyai dua kategori, yang pertama berdasarkan hubungan darah atau keturunan, dan yang kedua yaitu berdasarkan atas social budaya. Kesimpulannya seseorang bisa dikategorikan orang sunda yaitu di saat orang itu mengatakan dirinya sebagai orang sunda, dan dapat disepakati oleh orang sekitar sebagai orang sunda, dari daerah asal juga bertempat singgah di sekitaran orang sunda (Ekadjati, 2014:7).

Belajar dari orang sunda, seperti yang diungkapkan oleh Muhtadi et. al. (2017) mengungkapkan tentang budaya keseharian orang sunda, urang sunda melakukan aktivitas matematis berdasarkan pada nilai-nilai praktis yang inheren dalam kehidupannya. Hal seperti ini dapat dilihat dari kegiatan kebiasaan menaksir, mengukur dan dalam kegiatan pembuatan suatu pola. Selain itu, masyarakat sunda yang hidup di sekitar daerah Priangan Timur dalam melakukan aktivitasnya yang berkaitan dengan hewan peliharaan dan jual beli ikan gurame, kebanyakannya mereka sudah terbiasa dengan kegiatan perhitungan (Muzdalipah \& Yulianto, 2018). Dan juga Setiadi \& Imswatama (2017) menemukan bahwa di daerah sekitaran Sukabumi terdapat tradisi sunda yang biasa dilakukan dalam menghitung menentukan hari terbaik yang inti perhitungannya berdasarkan pada cara menghitung hari, bulan, tahun, pasaran, dan neptu. Phenomena pada orang sunda yang dimana masyarakatnya tetap melestarikan kegiatannya dari kebiasaan-kebiasanaan menghitung juga dapat dilihat dari observasi awal yang telah dilakukan oleh peneliti bahwa sebelum melakukan sesuatu, orang sunda terlebih dahulu diawali dengan aktivitas menghitung sebagai sesuatu hal yang pertama biasa dilakukan yang harus dan wajib untuk memulai suatu kegiatan. mulai dari hal-hal yang sederhana, seperti: menentukan kapan waktu yang pas untuk melangsungkan acara pernikahan, bercocok tanam, jual beli, memberikan anak sebuah nama, acara akad, menghitung hari yang baik ketika hendak akan memulai usaha, perhitungan daerah untuk memulai usaha, melakukan perhitungan disaat akan memulai pembangunan dan berpindah tenpat tinggal, menghitung hari yang terbaik pada saat hendak melakukan perjalanan jauh, perhitungan untuk barang yang hilang, hingga perhitungan berbagai kemungkinan-kemungkinan yang mungkin akan terjadi di waktu yang akan datang. Perhitungan tersebut tidak dapat dilakukan oleh sembarang orang, perhitungan ini biasanya dilakukan oleh seseorang yang disebut canoli, tokoh adat, sesepuh atau orang yang dianggap sudah ahli di bidangnya.

Fenomena-fenomena kebiasaan menghitung yang terjadi pada kegiatan masyarakat sunda tersebut merupakan salah satu cabang di bidang ilmu menghitung atau matematika, akan tetapi pada sebagian besar masyarakat sunda sering sekali tidak sadar bahwa mereka telah menggunakannya. Masyarakat sunda sering mempunyai berfikiran bahwa ilmu matematika merupakan salah satu keilmuan yang didapat dan dipelajari di lingkungan sekolah saja dan tidak pernah ada hubungannya dengan kegiatan menghitung yang suka mereka lakukan. Dengan kata lain mereka telah beranggapanbahwa tidak ada hubungannya antara ilmu menghitung dan adat atau budaya. Menurut Karnilah (2013) apabila pandangan tersebut tidak segera diminimalisir, kompleksitas permasalahan yang akan timbul antara lain yaitu berimbas kepada kegiatan belajar matematika itu sendiri, ilmu menghitung akan dianggap sebagai ilmu pengetahuan absolut, tak berpengaruh oleh adat atau kebiasaan (budaya), sehingga perlu menemukan cara menyampaikan konsep matematis pada ilmu menghitung yang berada di masyarakat supaya akibat dari permasalahan di atas tidak terjadi.

\section{METODE.}

Artikel ini ditulis dengan menggunakan metode studi pustaka yang merupakan telaah dari literatur dari jurnal, internet, dan kebiasaan orang sunda jaman dulu yang ada hubungannya dengan etnomatematika. Teknik analisis data dengan merangkum, menyajikan data, dan memberi kesimpulan.

\section{HASIL DAN PEMBAHASAN.}

Ada berbagai macam system perhitungan yang biasa dipergunakan oleh orang sunda. System tersebut di adopsi dari keyakinan orang India, Islam, jawa, dan budha. Cara perhitungan ini biasanya diperoleh dari seorang guru spiritual atau yang biasa disebut dengan ajengan. Hitungan yang biasa digunakan untuk hitungan hari yaitu dengan: 
1. Bismillah, kalimat bismillah ini bermakna kata yang paling awal dari segala sesuatu disaat akan mengawali suatu kegiatan.

2. Alhamdulillah, kalimat alhamdulillah bermakna kata sebagai rasa syukur atas segala ketenangan, suka cita yang telah diperoleh.

3. Astaghfirullah, kalimat astaghfirullah bermakna kalimat yang diucapkan disaat tertimpa cobaan atau musibah.

Dari ketiga kalimat hitungan-hitungan di atas, hari baik berada pada posisi pada kalimat kesatu dan kedua, sedangkan pada kalimat astaghfirullah adalah bilangan yang harus untuk dihindari. Misalkan, $\mathrm{Si} C$ dan si D hendak melangsungkan acara pernikahan di tanggal 8 , untuk mengetahui baik atau buruknya tanggal tersebut maka dapat dihitung dengan cara sebagai berikut:

Tanggal $1 \rightarrow$ Bismillah.

Tanggal $2 \rightarrow$ Alhamdulillah.

Tanggal $3 \rightarrow$ Astaghfirullah.

Tanggal $4 \rightarrow$ Bismillah.

Tanggal $5 \rightarrow$ Alhamdulillah.

Tanggal $6 \rightarrow$ Astaghfirullah.

Tanggal $7 \rightarrow$ Bismillah.

Tanggal $8 \rightarrow$ Alhamdulillah.

Jadi, dapat kita ketahui bahwa tanggal 8 adalah hari yang bagus untuk melangsungkan acara pernikahan, namun ketika tepat pada hitungan ketiga yaitu pada kalimat astaghfirullah maka diharapkan agar acara atau hajatnya di undur atau di majukan tanggal pernikahannya.

Akan tetapi ada juga yang biasa memakai lima hitungan dalam metode perhitungan ini. Namun cara perhitungan ini merupakan ilmu hitung "buhun" atau hitungan yang biasa digunakan orang tua zaman dahulu, yaitu:

1. Sri, kata sri ini memiliki urutan pertama, kata sri juga sering dikaitkan dengan nama seorang dewi padi dalam budaya sunda, yaitu bernama Dewi Sri. Jadi bisa juga diartikan dengan melimpahnya sandang pangan yang diperoleh. Sri memiliki makna yang bagus di perhitungan ini, bisa dimaknai dengan rezeki yang banyak, kesimpulannya kalimat sri ini yang tepat pada bilangan satu ini memiliki nilai baik disaat kita akan memposisikannya pada suatu hajat, rencana, keinginan, atau segala hal yang memerlukan untuk di hitung.
2. Lungguh, kata lungguh menempati posisi atau memiliki nilai dua, kata lungguh berkaitan dengan pangkat, jabatan, derajat, kemampuan, dan kekuatan. Lungguh berarti baik pada perhitungan ini. Kesimpulannya hitungan lungguh ini menempati bilangan dua ini memiliki makna yang berarti bagus disaat akan memposisikannya pada sebuah rencana, kemauan, hajat, atau suatu hal yang memerlukan suatu perhitungan.

3. Dunya, kata dunya menempati posisi atau memiliki nilai tiga, kata dunya berkaitan dengan rezeki, kekayaan, materi, dan harta yang banyak. Seperti dimisalkan semuah hajat atau pernikahan dilaksanakan menggunakan hasil perhitungan yang memiliki sisa nilai angka tiga, maka hajat atau pernikahan yang hendak diselenggarakan akan mudah mendapatkan biaya (modal) yang pastinya sesudah dilakukannya perhitungan. Kata dunya ini merupakan hitungan yang banyak diharapkan dalam semua keinginan, hajat, atau segala sesuatu yang mengharuskan dilakukannya perhitungan. Dunya memiliki makna yang berarti baik disaat kita akan memposisikannya di sebuah keinginan, rencana, atau sesuatu hal yang memerlukan perhitungan.

4. Lara, kata lara berada pada posisi hitungan ke empat, kata ini sering juga diartikan sebagai musibah atau keburukan, dari bentuk kesehatan, ketentraman lahir ataupun bathin. Kata lara ini pada dasarnya tidak diharapkan dalam setiap keinginan atau sesuatu hal yang memerlukan suatu hitungan. Hitungan pada bilangan lara ini memiliki nilai yang tidak baik disaat akan memposisikannya pada suatu keinginan, atau sesuatu perkara yang memerlukan hitungan.

5. Pati, kata pati berada pada posisi hitungan ke lima, hitungan terakhir yang ada di system bilangan ini. Pati biasa diartikan mati. Tetapi tidak semata-mata menyangkut pautkannya dengan kematian. Mati disini dapat diartikan mati dalam mencari perkara duniawi, mati dalam artian akan terjadinya kerusakan dalam berumah tangga, mati dalam artian semua perkara yang bermakna suatu keadaan 
yang terburuk, pati disini bisa bermakna sebagai ikatan yang berada pada orang yang sudah meninggal yang jumlahnya lima, jumlah inilah yang kebanyakan orang dianggap sebagai nilai atau bilangan yang bersifat apes atau sial. Artinya, bilangan ini merupakan bilangan yang tidak diharapkan dalam setiap rencana atau suatu perkara yang memerlukan suatu hitungan. Hitungan pati memiliki makna bilangan yang tidak baik ketika akan memposisikannya di sesuatu keinginan rencana, atau suatu perkara yang memerlukan hitungan.

Rancangan atau tatacara menghitung agar mendapatkan nilai hitungan seperti di atas, antara lain. Misal, seseorang mempunyai rencana akan berpindah tempat tinggal atau rumah pada tanggal 12 safar. Maka kita bagi nilai 12 oleh 5 (urutan bilangan) hasilnya adalah 2, sisanya yaitu 2 . Bilangan dua ini berposisi pada bilangan kata lungguh.

$12: 5=2$ sisanya 2 .

Ramalan jodoh atau pasangan dapat ditentukan berdasarkan pada nama dan hari lahirnya. Tetapi, untuk mengetahuinya memerlukan berbagai sandi perhtungan.

a. Sandi babasan.

Sandi babasan adalah suatu sandi yang ddi dalamnya terdapat beberapa nomor urut yang begitu berpengaruh. Sandi ini biasanya dipakai sesudah nilai hasil perhitungannya dibagi dengan tujuh, hasilnya tinggal di cocokkan di nomor urutan dalam sandi babasan, dengan demikian maka dapat dilihat cocok atau tidaknya calon pengantin atau pasangan jika hidup berumah tangga. sandinya yaitu sebagai berikut:

Tabel 1. Sandi Babasan

\begin{tabular}{|c|c|c|}
\hline No. & Sandi. & Makna. \\
\hline 1. & Pisang punggel. & Buruk. \\
\hline 2. & Lumbung gumilang & Buruk \\
\hline 3. & Tunggak kasemi. & Buruk \\
\hline 4. & Satria lalaku. & Baik. \\
\hline 5. & Sangga waringin. & Baik. \\
\hline 6. & Paparingan kebek. & Baik. \\
\hline 7. & $\begin{array}{c}\text { Ratu sabdaning } \\
\text { pandita. }\end{array}$ & Baik. \\
\hline
\end{tabular}

b. Sandi huruf.
Sandi huruf adalah sandi yang untuk setiap hurufnya mempunyai nilai yang berbedabeda. Adapun nilai-nilai itu sudah ditentukan juga diurutkan di aturan tulisan jawa yang tidak bisa dibuat-buat sesuka hati. Berikut adalah nilai-nilai yang sesuai dengan aturan aksara jawa.

Tabel 2. Sandi Huruf

\begin{tabular}{|l|l|}
\hline $\mathrm{Ha} \rightarrow 1$ & $\mathrm{~Pa} \rightarrow 11$ \\
\hline $\mathrm{Na} \rightarrow 2$ & $\mathrm{Dha} \rightarrow 12$ \\
\hline $\mathrm{Ca} \rightarrow 3$ & $\mathrm{Ja} \rightarrow 13$ \\
\hline $\mathrm{Ra} \rightarrow 4$ & $\mathrm{Ya} \rightarrow 14$ \\
\hline $\mathrm{Ka} \rightarrow 5$ & $\mathrm{Nya} \rightarrow 15$ \\
\hline $\mathrm{Da} \rightarrow 6$ & $\mathrm{Ma} \rightarrow 16$ \\
\hline $\mathrm{Ta} \rightarrow 7$ & $\mathrm{Ga} \rightarrow 17$ \\
\hline $\mathrm{Sa} \rightarrow 8$ & $\mathrm{Ba} \rightarrow 18$ \\
\hline $\mathrm{Wa} \rightarrow 9$ & $\mathrm{Tha} \rightarrow 19$ \\
\hline $\mathrm{La} \rightarrow 10$ & $\mathrm{Nga} \rightarrow 20$ \\
\hline
\end{tabular}

Begitu juga sandi huruf-huruf tersebut didapat dari tulisan jawa yang bisa kita cermati pada gambar di bawah ini.

\begin{tabular}{|c|c|c|c|c|}
\hline tha & na & ca & ra & ka \\
\hline บิ & 1ถ & (ग) & थ & की \\
\hline da & ta & sa & wa & 18 \\
\hline (С) & חתו & (2) & (几 & ดบ \\
\hline pro & dha & ja & $y=$ & nya \\
\hline (U & (W) & as & טU & ละทา \\
\hline $\mathrm{ma}$ & $g$ & ba & tha & nga \\
\hline हा & ขก & ตราก & हो & an \\
\hline
\end{tabular}

Namun, pada huruf-huruf vokal, di karenakan tidak tercantum di huruf jawa, jadi bagi seluruh huruf-huruf vokal (A, I, U, E, O) memiliki hasil 0 juga untuk semua hurufhuruf konsonan yang tidak tercantum di tulisan jawa seperti huruf $\mathrm{F}, \mathrm{Q}, \mathrm{V}, \mathrm{X}$, dan $\mathrm{Z}$ maka bilangannya di samakan dengan hurufhuruf yang terdapat di tulisan jawa itu sendiri yang memiliki cara pelafalan yang sama. Seperti huruf F dan V memiliki cara pelafalan yang mirip dengan huruf P yaitu 11. Begitup juga dengan huruf yang lainnya.

c. Sandi hari.

Sandi hari adalah sandi yang untuk seluruh kelahiran memiliki bilangannya sendiri yaitu:

Tabel 3. Sandi Hari

\begin{tabular}{|c|c|c|}
\hline No. & Hari. & Nilai. \\
\hline 1. & Minggu. & 5 \\
\hline 2. & Senin. & 4 \\
\hline
\end{tabular}




\begin{tabular}{|c|c|c|}
\hline 3. & Selasa. & 3 \\
\hline 4. & Rabu. & 7 \\
\hline 5. & Kamis. & 8 \\
\hline 6. & Jum'at. & 6 \\
\hline 7. & Sabtu. & 9 \\
\hline
\end{tabular}

d. Aturan menghitung.

1. Hitung nama calon pasangan dari mempelai pria menggunakan sandi huruf.

2. Hitung nama calon pasangan dari mempelai wanita menggunakan sandi huruf.

3. Hitung semua nilai pada aturan pertama dan kedua, dan setelahnya dibagi 7 sisanya, diakurkan dengan nomor urutan yang ada di sandi babasan dan jika hasil akhirnya 0 , maka akurkan pada nomor urutan 7.

4. Hitung semua nilai hari kelahiran calon dari mempelai wanita dan calon dari mempelai pria yang didasarkan pada sandi hari.

5. Hitung semua nilai pada urutan ketiga dan keempat lalu setelahnya dibagi 7 sisanya lalu di akurkan berdasarkan sandi babasan.

6. Hitung nama daerah asal dari kedua calon berlandaskan pada sandi huruf lalu tambahkan dengan jumlah nilai hari kelahiran juga hasil nilai dari nama, setelahnya dibagi 7 hasilnya, akurkan berdasarkan pada sandi babasan.

7. Jika seluruh jumlahnya menunjukkan baik, maka begitupun untuk kedua calon pasangan. Tetapi, jika salah seorang ada yang hasil perhitungannya buruk atau bahkan menunjukkan hasil yang tidak baik, maka tidak baik juga bagi keduanya.

Contoh: Pak Jamaludin yang lahir pada hari sabtu akan menikahi Ibu Hindun yang lahir pada hari senin. Mereka tinggal dikampung Cibungur.

Cara hitungnya sebagai berikut:

$\mathrm{Ja}+\mathrm{ma}+\mathrm{lu}+\operatorname{din}=13+16+10+6=45$

Hin + dun $=1+6=7$

Jumlah $=45+7=52$ $\frac{52}{7}=7$ sisa 3 bermakna jika diakurkan ke sandi babasan maka menempati urutan ketiga adalah Tunggak Kasemi berarti buruk.

Hari kelahiran kedua mempelai.

Sabtu $\rightarrow 9$

Senin $\rightarrow 4$

Hasil hari kelahiran di tambah hasil dari perhitungan nama

$13+52=65$

$\frac{65}{7}=6$ sisa 2

2 = Lumbung Gumilang artinya kurang baik.

Tempat tinggal keduanya

$\mathrm{Ci}+$ bu + ngur $=3+18+20=41$

$41+65=106$

$\frac{106}{7}=15$ sisa 1

$1=$ Pisang Punggel yang berarti kurang baik. Jadi, kesimpulannya kurang baik karena nama, hari lahir, dan temapt tinggal mereka.

\section{Konsep matematika pada hitungan sunda.}

Berdasarkan kegiatan matematika yang dilakukan orang sunda, di temukan beberapa pola dan konsep matematika, pola tersebut membentuk pola 3 , dan pola 5 adalah siklus yang didapat dari perhitungan tanggal untuk pernikahan, sedangkan pola 7 yaitu siklus hasil yang diperoleh dari menghitung kecocokan pasangan pengantin. Teori matematika yang di dapat dari kebiasaan menghitung orang sunda yaitu teori aritmatika modulo juga barisan aritmatika. Pada teori aritmatika modulo.

Berlandaskan kepada penjelasan modulo adalah proses perhitungan yang memperoleh sisa hasil bagi pada sebuah angka terhadap angka yang lain.

- Misalya $b$ dan $n$ angka bulat $(n>0)$. Operasi $b$ mod n ( dibaca "b modulo n") menghasilkan sisa jika dibagi oleh $n$.

- Notasi: $\mathrm{b} \bmod \mathrm{n}=\mathrm{r}$ sedemikian sehingga $\mathrm{b}=$ $\mathrm{nq}+\mathrm{r}$, dengan $0 \leq \mathrm{r}<\mathrm{n}$.

- $\quad \mathrm{N}$ disebut modulus atau modulo, dan hasil aritmatika modulo $\mathrm{n}$ terletak di dalam himpunan $(0,1,2, \ldots, n-1)$.

\section{Contoh:}
a. $23 \bmod 5=3 \quad(23=5.4+3)$
b. $\quad 27 \bmod 3=0 \quad(27=3.9+0)$
c. $6 \bmod 8=6 \quad(6=8.0+6)$
d. $\quad 0 \bmod 12=0 \quad(0=12.0+0)$
e. $\quad-39 \bmod 13=3 \quad(-39=13(-3)+0)$ 
Konsep aritmatika modulo pada proses menghitung yang terdapat pada kegiatan orang sunda diperoleh dari model matematika yang terdapat pada kebiasaan menghitung suku sunda. Pemodelan matematika tersebut di temukan agar memperoleh sisa hasil bagi pada pada setiap proses menghitung. Berikut adalah pemisalan dan pemodelan yang di peneliti peroleh:

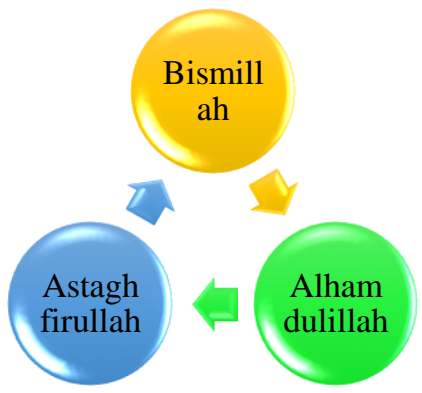

Gambar 2. Siklus perputaran bilangan pada hitungan penentuan tanggal dan hari oleh ajengan (modulo 3)

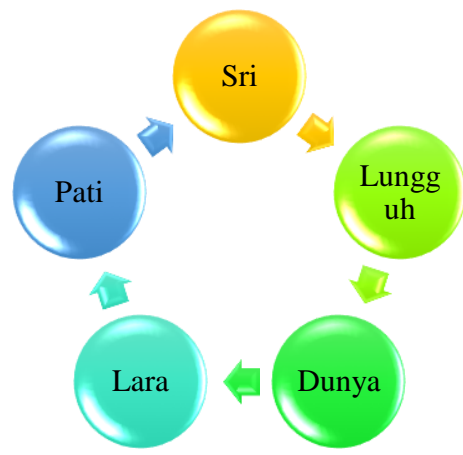

Gambar 3. Siklus bilangan pada hitungan menentukan perkawinan proses menentukan waktu atau hari (modulo 5)

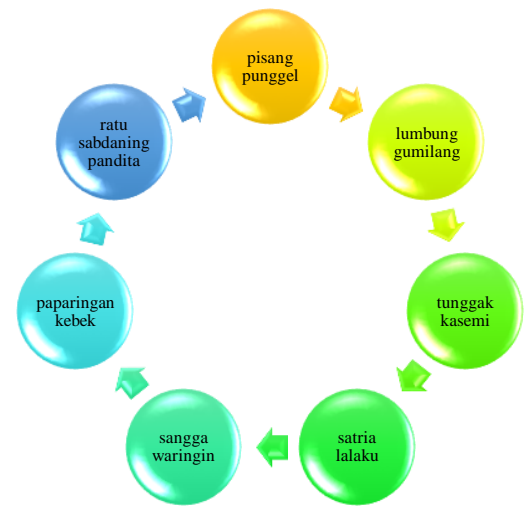

Gambar 4. Siklus perputaran bilangan pada hitungan kecocokan calon pasangan (modulo 7)

Pada modulo 7.

Sebelum masuk ke dalam teori modulo, sebelumnya lakukan proses menghitung pada tahapan-tahapan berikut sesuai dengan contoh.

Jamaludin $=\mathrm{Ja}+\mathrm{ma}+\mathrm{lu}+\operatorname{din}$

$$
\begin{aligned}
& =13+16+10+6 \\
& =45 \\
\text { Hindun } & =\text { hin }+ \text { dun } \\
& =1+6 \\
& =7
\end{aligned}
$$

Kedua nama pasangan dijumlahkan:

Jamaludin + Hindun $=45+7=52$

Setelah hasilnya di dapatkan setelahnya lakukan proses menghitung dengan menggunakan teori aritmatika modulo.

Langkah pertama: $52: 7=7$ sisanya 3 atau bisa juga di tulis

$52-7 \times 7=3$
Langkah kedua $\quad 52=7 \times 7+3$

Berdasarkan teori modulo sebagai berikut:

- $r \bmod m . n \quad r=m z+n$

- $52 \bmod 73$ sedemikian sehingga $52=7 \times 7+$ 3

\section{Pada modulo 5.}

Contoh : pak Jamaludin mempunyai keinginan untuk berpindah rumah atau tempat tinggal tanggal 12 safar. Langkah pertama : $12: 5=2$ sisa 2 atau bisa juga di tulis

$$
12-5 \times 2=2
$$

Langkah kedua: $12=2 \times 5+2$

Berdasarkan teori modulo, yaitu:

- $r \bmod m \mathrm{n}=\mathrm{mz}+\mathrm{n}$

- $\quad 12 \bmod 5=2$ sedemikian sehingga $12=5 \times 2$

$$
+2
$$

\section{Pada modulo 3.}

Contoh : ketika A dan B akan melaksanakan pernikahan pada tanggal 8 .

Langkah pertama : $8: 3=2$ sisa 2 atau bisa juga di tulis

$$
8-2 \times 3=2
$$

Langkah kedua $: 8=2 \times 3+2$

Berdasarkan konsep modulo, yaitu:

- $r \bmod m \mathrm{n} \quad \mathrm{r}=\mathrm{mz}+\mathrm{n}$

- $8 \bmod 3=2$ sedemikian sehingga $8=3 \times 2+$ 2

Konsep barisan aritmatika.

Barisan aritmatika ialah barisan bilangan yang memiliki beda ataupun selisih yang tetap diantara dua suku barisan dan berurutan.

Contoh: pak Jamaludin mempunyai hajat untuk berpindah tempat tinggal pada bulan safar. 
Dengan memanfaatkan teori aritmatika di peroleh

$\mathrm{Un}=\mathrm{a}+(\mathrm{n}-1) \mathrm{b}$

Penjelasan:

$\mathrm{Un}=$ mencari menentukan angka awal dan selanjutnyanya tanggal baik untuk digunakan melakukan berpindah tempat tinggal.

$\mathrm{a}=3$ merupakan angka yang diperoleh dari urutan dunya yaitu urutan ke-tiga yang dijadikan tolak ukur bagusnya tanggal untuk melakukan berpindah tempat tinggal.

$\mathrm{b}=5$ di ambil dari bahasan (sri, lungguh, dunya, lara, dan pati).

$$
\begin{aligned}
\mathrm{U}_{2} & =3+(2-1) 5 \\
& =8
\end{aligned}
$$

Tanggal 8 merupakan tanggal yang baik ke-dua untuk melakukan berpindah tempat tinggal.

$\mathrm{U}_{3}=3+(3-1) 5$

$=13$

Tanggal 13 adalah tanggal ketiga yang baik untuk berpindah tempat tinggal. dst

\section{PENUTUP.}

\section{Simpulan.}

Kesimpulan dari artikel ini menunjukkan terdapat adanya unsur-unsur matematika dalam kebiasaan orang sunda. Hal ini terbukti karena adanya teori matematika yaitu teori barisan aritmatika dan artimetika modulo pada kebiasaan orang sunda dalam perhitungan penentuan tanggal pernikahan dan perhitungan penentuan kecocokan pasangan pengantin.

\section{DAFTAR PUSTAKA.}

Ekadjati, E. S (2014). Kebudayaan sunda suatu pendekatan sejarah jilid 1. Jakarta: pustaka jaya.

Karnilah, N. (2013). Study ethnotematics: pengungkapan system bilangan masyarakat adat baduy. [Skripsi]. Universitas Pendidikan Indonesia.

Aini, E. P., Masykur, R., \& Komarudin, K. (2018). Handout Matematika berbantuan Etnomatematika Berbasis Budaya Lokal. Desimal: Jurnal Matematika, 1(1), 73-79. https://doi.org/10.24042/djm.v1i1.1950

Komarudin, K., Puspita, L., Suherman, S., \& Fauziyyah, I. (2020). Analisis Pemahaman Konsep Matematis Peserta Didik Sekolah Dasar: Dampak Model Project Based
Learning Model. DIDAKTIKA TAUHIDI: Jurnal Pendidikan Guru Sekolah Dasar, 7(1), 43-53.

Lestari, D., Komarudin, K., Mujib, M., \& Mardiyah, M. (2020). Mathematical module based on islamic values as a development of contextual teaching and learning (CTL). Math Didactic: Jurnal Pendidikan Matematika, 6(3), 344-354.

Novitasari, C. D., Anggoro, B. S., \& Komarudin, K. (2019). Analisis Sarang Lebah Madu dalam Geometri Matematika dan Al-Qur'an. AKSIOMA: Jurnal Program Studi Pendidikan Matematika, 8(1).

Wahyuni, A., \& Pertiwi, S. (2017). Etnomatematika dalam ragam hias melayu. Math Didactic: Jurnal Pendidikan Matematika, 3(2), 113118.

Masduki (2010). Upacara perkawinan adat sunda di kecamatan cicalengka kabupaten bandung. Patanjala 2(3), 377-393.

Munir, R. (2004). Teori bilangan (number theory). Bahan kuliah ke-3. Departemen Teknik informatika ITB.

Setiadi, D. \& Imswatama, A. (2017). Pola bilangan matematis perhitungan weton dalam tradisi jawa dan sunda. Jurnal ADHUM, 7(2).

Sugiyono (2017). Metode penelitian Pendidikan pendekatan kuantitatif kualitatif dan R\&D. Bandung: Alfabeta.

Suryaatmana, E. Darsa, U. A, Erlyane, A, Wartini, T. (1993). Paririmbon sunda. Jakarta: Depdikbud direktoret jendral kebudayaan direktorat sejarah dan nilai tradisional bagian proyek penelitian dan pengkajian kebudayaan nusantara. 